\title{
Phaeotremella foliacea comb. nov. (Tremellales, Tremellomycetes, Agaricomycotina)
}

\author{
Wedin $\mathrm{M}^{1}$, Zamora $\mathrm{JC}^{2}$ and Millanes $\mathrm{AM}^{3}$ \\ ${ }^{I}$ Department of Botany, Swedish Museum of Natural History, P.O. Box 50007, SE-104 05 Stockholm, Sweden. \\ mats.wedin@nrm.se \\ ${ }^{2}$ Departamento de Biología Vegetal II, Facultad de Farmacia, Universidad Complutense de Madrid, E-28040 Madrid, \\ Spain \\ ${ }^{3}$ Departamento de Biología y Geología, Física y Química Inorgánica, Universidad Rey Juan Carlos, C/ Tulipán s.n., E- \\ 28933 Móstoles, Spain
}

Wedin M, Zamora JC, Millanes AM 2016 - Phaeotremella foliacea comb. nov. (Tremellales, Tremellomycetes, Agaricomycotina). Mycosphere 7(3), 295-296, Doi 10.5943/mycosphere/7/3/4

\begin{abstract}
The new combination Phaeotremella foliacea (Pers.) Wedin, J.C. Zamora \& Millanes is coined and taken up as the current name for one of the most common species of the recently resurrected genus Phaeotremella Rea.
\end{abstract}

Key words - Tremella - nomenclature

\section{Introduction}

Recently, Liu et al. (2016) presented a major reclassification of the Tremellomycetes (Agaricomycotina) and a number of substantial changes to the ordinal, family and generic delimitations were made, based on recent progress in the understanding of the phylogeny of this large and important basidiomycete group. Liu et al. (2016) were the first to attempt a full integration of the classifications of yeasts and filamentose representatives, and presented a sevenmarker phylogeny including the majority of yeast-forming and filamentous taxa. Among many new discoveries was that the Tremella foliacea-group should be recognized as a distinct genus, something quite clear already in Millanes et al. (2011). For this group, the name Phaeotremella Rea (Rea 1912) was available and taken up by Yurkov \& Boekhout in Liu et al. (2016). Seven species were also combined into Phaeotremella in Liu et al. (2016), but despite pointing out that the type species of Phaeotremella Rea (Phaeotremella pseudofoliacea Rea) is currently by most authors treated as a synonym to the older "Tremella" foliacea Pers. (Donk 1966, Roberts 1999), the necessary combination based on the older name was unfortunately omitted. Here we rectify this, and include a brief discussion on the current species taxonomy of Phaeotremella.

\section{Nomenclature}

Phaeotremella Rea, Trans. Br. Mycol. Soc. 3: 377. 1912. emend. A.M. Yurkov \& Boekhout, Stud. Mycol. 81: 137. 2016

MycoBank 18243

Type species: Phaeotremella pseudofoliacea Rea, Trans. Br. Mycol. Soc. 3: 377. 1912. 
Phaeotremella foliacea (Pers.) Wedin, J.C. Zamora \& Millanes, comb. nov.

MycoBank MB 816932

Basionym: Tremella foliacea Pers., Observationes mycologicae 2: 98. 1800.

\section{Discussion}

Species delimitations in Phaeotremella are currently very poorly understood. Phaeotremella ("Tremella") foliacea is considered a widely distributed and very variable species (Donk 1966, Roberts 1999). We assume that species delimitation studies may affect the current species concepts considerably in this group. Although Donk (1966) treated P. foliacea and P. pseudofoliacea as synonyms and Roberts (1999) stated that $P$. foliacea and $P$. pseudofoliacea are morphologically undistinguishable, our experience indicates that we have to consider the possibility that several species currently are hiding under $P$. foliacea, and detailed studies are in progress.

\section{Acknowledgements}

This work was supported by the grants 155/2011 and 2016-27 4.3 from the Swedish Taxonomy Initiative (administered by the Swedish Species Information Centre).

\section{References}

Donk MA. 1966 - Check list of European hymenomycetous Heterobasidiae. Persoonia 4, 145-335. Liu XZ, Wang QM, Göker M, Groenewald M, Kachalkin AV, Lumbsch HT, Millanes AM, Wedin M, Yurkov AM, Boekhout T, Bai FY. 2016 - Towards an integrated phylogenetic classification of the Tremellomycetes. Studies in Mycology 81, 85-147.

Millanes A, Diederich P, Ekman S, Wedin M. 2011 - Molecular phylogeny and character evolution in the jelly fungi (Tremellomycetes, Basidiomycota, Fungi). Molecular Phylogenetics and Evolution 61, 12-28.

Persoon DHC. 1800 - Observationes mycologicae 2. Lipsiae et Lucernae.

Rea C. 1912 - New and rare British Fungi. Transactions of the British Mycological Society 3, 376380.

Roberts P. 1999 - British Tremella species II. Tremella encephala, T. steidleri, and T. foliacea. The Mycologist 13, 127-131. 